Check for updates

Cite this: RSC Adv., 2019, 9, 5908

Received 27th August 2018

Accepted 11th February 2019

DOI: $10.1039 / \mathrm{c} 8 \mathrm{ra07136e}$

rsc.li/rsc-advances

\section{Stability and pervaporation characteristics of PVA and its blend with PVAm membranes in a ternary feed mixture containing highly reactive epichlorohydrin}

\author{
Shivshankar Chaudhari, ${ }^{a}$ YongSung Kwon, ${ }^{a}$ MinYoung Shon, (D) *a SeungEun Nam ${ }^{b}$ \\ and Youln Park ${ }^{\mathrm{b}}$
}

In order to find an alternative for classical distillation in the recovery of ECH/IPA from azeotropic ECH/IPA/ water (50/30/20 w/w, \%) mixtures, a pervaporation process has been applied. Membranes from the crosslinking of poly(vinyl alcohol)/poly(vinyl amine) (PVA/PVAm) were prepared, and then the membrane stability and pervaporation efficiency of the crosslinked PVA/PVAm membranes were studied for highly reactive $\mathrm{ECH}$ systems containing a ternary feed mixture. From the Fourier-transform infrared (FT-IR) spectroscopy analysis, it was observed that all of the membranes were chemically stable for 15 days of immersion in a $50: 30: 20 \mathrm{ECH} / \mathrm{IPA} /$ water $\left(\mathrm{w} / \mathrm{w}\right.$, \%) feed mixture at $60{ }^{\circ} \mathrm{C}$. The degree of membrane swelling increased with increasing PVAm content in the membrane composition, water content in the feed composition, and feed temperature, which was attributed to the increase in the number of hydrophilic sites in the membrane. The field-emission scanning electron microscopy (FE-SEM) study revealed that higher PVAm content membranes (PVAm1.0 and PVAm1.5) show polymer phase extraction in ECH/IPA/water $(50: 30: 20)(\mathrm{w} / \mathrm{w}, \%)$ at $60{ }^{\circ} \mathrm{C}$ in long-term stability tests. The pervaporation dehydration characteristics for all of the membranes with the feed comprising an ECH/IPA/water (50:30:20 by weight) azeotropic mixture at $30{ }^{\circ} \mathrm{C}$ were examined and excellent pervaporation dehydration efficiency was found. Quantitatively, the flux increased from 0.025 to $0.32 \mathrm{~kg}\left(\mathrm{~m}^{2} \mathrm{~h}\right)^{-1}$ and the separation factor decreased from 1908 to 60 with increasing PVAm content in the blended membrane.

\section{Introduction}

Due to the great demand for energy used in the conventional separation technologies, in recent years, hydrophilic membranes have been frequently employed in various alternative membrane-based separation technologies. For example, they are used in pervaporation for the dehydration of organic solvents and various vapor permeation technologies ${ }^{1-5}$ for the removal of water vapor from various gases. The process of pervaporation (PV) is characterized by the concentration gradient of components in the membrane, which produces a vapor permeate and liquid retentate by partial vaporization through a non-porous permselective membrane. The driving force for permeants to travel across the membrane from the feed to the permeate is obtained by exerting a difference in the partial pressure of the permeants on either side of the membrane. ${ }^{6,7}$ Mass transport in the pervaporation membrane

${ }^{a}$ Department of Industrial Chemistry, Pukyong National University, San 100, Yongdang-Dong, Nam-Gu, Busan 608-739, Korea. E-mail: myshon@pknu.ac.kr; Fax: +8251629 6429; Tel: +82516296440

${ }^{b}$ Center for Membranes, Korea Research Institute of Chemical Technology, 141 Gajeong-ro, Yuseong-gu, Daejeon 305-600, Korea can be explained by the solution diffusion model. ${ }^{6}$ Generally there are three steps through which separation takes place in the pervaporation membrane.

(1) In the first step, selective sorption of components to the feed side (liquid) of the membrane.

(2) Selective diffusion of the components across the membrane (liquid).

(3) Desorption of the components to the permeate side of the membrane in the vapor phase.

The application of PV has been broadly extended to various industries ranging from chemical, ${ }^{8}$ food, ${ }^{9}$ and pharmaceutical ${ }^{10}$ to petrochemical industries. ${ }^{11}$ Pervaporation is a well-known alternative method to classical distillation, which is not only limited to dehydration of liquid hydrocarbons to produce highpurity organics like ethanol, ${ }^{12}$ isopropanol, ${ }^{13,14}$ ethylene glycol, ${ }^{15}$ etc., but has also been employed to enhance the conversion rate of esterification reactions. ${ }^{16,17}$ Additionally, it has also been used in the extraction of aroma compounds from alcoholic beverages, ${ }^{18,19}$ separation of aromatics from gasoline in the petroleum industry, etc. ${ }^{20,21}$

Epichlorohydrin (ECH) containing epoxide and organochlorine moieties is a highly reactive electrophilic compound used 
in the production of glycerol, plastics, and epoxy resins. ${ }^{22,23}$ Epoxy resin is prepared by polymerization of ECH with phenol. In the process proposed herein, biphenol-A (BPA) is used as a phenol resin and isopropyl alcohol (IPA) is used as the solvent. Excess ECH is included in the raw material to control the molecular weight of the produced epoxy resin. After reaction, water, a series of chlorine impurities, and by-products, along with the ECH/IPA raw materials, were present in a mixture with the target product epoxy resin. ECH and IPA can be recovered via vacuum distillation and recycled as raw materials. However, the impurity content gradually increases after repeated reuse. During the recovery of ECH and IPA by distillation, ECH and IPA form a ternary azeotropic mixture with water impurities $(\mathrm{ECH} /$ IPA/water, $50: 30: 20(\%) \mathrm{w} / \mathrm{w})$, making it difficult to purify ECH and IPA individually with high purity. Therefore, in terms of energy efficiency and reuse of unreacted materials, improvements to this process are required. Furthermore, ECH can cause environmental hazards because it is carcinogenic in nature ${ }^{\mathbf{2 4 , 2 5}}$ and can have severe adverse effects on ecological systems if its effluent comes into contact with the environment. A hybrid process involving moisture removal by pervaporation and the recovery and purification of ECH and IPA via distillation can improve the ecofriendly energy efficiency and the product competitiveness by reducing the cost associated with the epoxy resin manufacturing process.

Nevertheless, since ECH is a highly reactive chemical, selection of a stable polymeric membrane material for pervaporation in the ECH/IPA/water novel feed system is a challenging task. The main requirement of polymers for dehydration applications is that they should have selective sorption and selective diffusion towards water. ${ }^{\mathbf{6} 26}$ For obtaining high sorption selectivity, it is necessary to use polymers containing sorptive centers capable of specific interaction with water. The most common interactions are dipole-dipole, hydrogen bonding, and ion-dipole. To achieve high diffusion selectivity, the rigidity and ordering of the polymer structure, along with its stability in the feed system, are important. There are currently more than 350 publications related to PV and commercial membranes based on poly(vinyl alcohol) (PVA) are readily available for pervaporation dehydration. ${ }^{27,28}$

PVA membranes undergo excessive swelling in aqueous feed mixtures, so they are commonly modified using different methods such as polymer grafting, crosslinking, blending with different polymers and the formation of PVA copolymers. ${ }^{29-31}$ It has been observed that membranes prepared from the blending of different polymers show promising pervaporation performance, because, in blended membranes, the intrinsic chemical, physical, mechanical, and morphological properties of each polymer can be combined, so it is possible to design desirable membrane properties through blending. Poly(vinyl amine) has a higher amount of primary amine groups in comparison to chitosan, poly(ethyleneimine) and poly(allyl amine), in its polymer backbone $\mathrm{b}^{32}$ and it allows the preparation of very hydrophilic membranes. However, because PVAm (commercially available as PVAm $\mathrm{HCl}$ ) is usually sticky, swollen, and highly viscous, it is not possible to form a membrane film using poly(vinyl amine) alone. On the other hand, PVA has excellent membrane forming properties, a high tensile strength, flexibility, robust nature and stability in organic solvents. Both PVAm and PVA are hydrophilic in nature, containing abundant hydrophilic functional groups in their main chains $\left(\mathrm{NH}_{2}\right.$ and $\mathrm{OH}$ ); consequently, the combination of these polymers may yield a high-quality pervaporation membrane for dehydration processes. Therefore, in our recent reports we have studied membranes prepared from blends of PVA and poly(vinyl amine) (PVAm) for pervaporation dehydration of water/isopropanol feed mixtures. ${ }^{14,33}$ Additionally, Deng and Hagg et al. have explored a similar type of membrane composition in the application of a fixed carrier transport (FSC) membrane for $\mathrm{CO}_{2}$ separation. $^{34,35}$ PVA/PVAm blends provide good membrane stability and mechanical strength because PVAm has a high density of primary amine moieties that exhibit a stable polymer network with PVA during blending by entanglement of the PVA chains with the PVAm chains. Additionally, after chemical crosslinking, very stable networks can be formed because the PVA/PVAm blend has numerous reactive amino and hydroxyl functional groups available in the polymer backbones for modification. However, in the practical application of pervaporation for the removal of water from the highly reactive $\mathrm{ECH} /$ IPA/water feed mixture by PVA/PVAm blended membranes consisting of hydroxyl and amine functional groups, it is more necessary to study the long-term stability of the membranes.

Therefore, in this study, our focus is mainly on the stability study and pervaporation dehydration characteristics of glutaraldehydecrosslinked PVA and PVA/PVAm blend membranes in the novel ECH/IPA/water feed system. To the best of our knowledge, this approach has not yet been reported in the literature. The characterization of the prepared membranes was performed by swelling studies, scanning electron microscopy (SEM), and Fouriertransform infrared (FTIR) spectroscopy. A pervaporation separation test was conducted for the azeotropic ternary feed mixture, ECH/IPA/water (50:30:20, w/w), using the PVA membrane and PVA/PVAm blend membranes with different PVAm contents.

\section{Experimental}

\section{Materials}

PVA (98-99\% hydrolyzed; 88 000-97 $000 \mathrm{~g} \mathrm{~mol}^{-1}$ ) was procured from Alfa Aesar, USA. Polyvinyl amine (10 wt\% solution, $340000 \mathrm{~g} \mathrm{~mol}^{-1}$ ) was donated by BASF, Indonesia. The rest of the chemicals, i.e. glutaraldehyde, hydrochloric acid $(36.0 \%, \mathrm{w} / \mathrm{w})$, IPA $(99.5 \%, w / w)$, and ECH $(99.5 \%, w / w)$, were supplied by DaeJung Chemicals \& Metal Co, Korea. Deionized water (Puris, RO system) was used to prepare the different feed compositions for pervaporation and swelling degree measurement analysis.

\section{Preparation of crosslinked PVA and PVA/PVAm blend membrane samples}

PVA and PVA/PVAm blend membranes were prepared according to the procedure described in our previous paper. ${ }^{33}$ One PVA membrane and three glutaraldehyde-crosslinked PVA/PVAm blended membranes were prepared. The designation and details of the PVA and PVAm contents for the blended 
membranes are shown in Table 1 . Briefly, PVA ( $4 \mathrm{~g})$ powder was dissolved in $96 \mathrm{~g}$ of water with continuous stirring at $75^{\circ} \mathrm{C}$ for $6 \mathrm{~h}$. The solution was later filtered and kept as it was overnight in order to remove any air bubbles. Subsequently, the next day, the solution was cast onto a Petri dish and dried at room temperature. The dried film was pulled from the Petri dish and crosslinked in a crosslinking bath containing 90/10/4/1 vol\% IPA/water/glutaraldehyde (25\%) solution and catalytic hydrochloric acid at $50{ }^{\circ} \mathrm{C}$ for $1 \mathrm{~h}$. Later, the obtained membrane was washed in water to remove the catalyst and unreacted glutaraldehyde and dried at $30{ }^{\circ} \mathrm{C}$ in a drying oven prior to use. For the preparation of PVA/PVAm blended membranes, $4 \mathrm{wt} \%$ PVAm solution was prepared by the dilution of a $10 \mathrm{wt} \%$ readymade PVAm solution and blended in different amounts (please refer to Table 1) with PVA solution. The blended solutions were mixed properly by stirring at room temperature for $24 \mathrm{~h}$, and for casting and crosslinking the same procedure was followed as that for the crosslinked PVA sample. All the blended membranes were preserved at $30{ }^{\circ} \mathrm{C}$ in a drying oven prior to use.

\section{Membrane characterization and stability test}

Fourier-transform infrared (FTIR) spectroscopy. The molecular structures of the membranes were characterized by FTIR (ATR mode) spectroscopy using a Nicolet iS10 (USA) spectrometer over the scanning range of $400-4000 \mathrm{~cm}^{-1}$ with a resolution of $2 \mathrm{~cm}^{-1}$. Spectra for all the samples were collected after 32 scans. Membrane stability for the ECH-containing feed was also determined using FTIR measurements.

Field-emission scanning electron microscopy (FE-SEM). The surface and cross-sectional morphologies of the membranes were observed using FE-SEM [Teskan, Czech, Vega II, and LSU] analysis. The membrane samples were made conductive for analysis by gold sputter coating.

Stability study of the membranes. All the homogenous membrane samples (dried at $40{ }^{\circ} \mathrm{C}, 24 \mathrm{~h}$ ) were weighed and immersed in $50 \mathrm{~mL} \mathrm{ECH/IPA/water}(50: 30: 20$, w/w) solution at $60{ }^{\circ} \mathrm{C}$ for 15 days. For evaluation of the gain/loss in weight (due to chemical reaction or extraction), the membranes were weighed every 5 days after drying in an oven (Memmert, UN55) at $40{ }^{\circ} \mathrm{C}$ for $24 \mathrm{~h}$, and the difference between the initial and final weights was measured. For accuracy, two measurements were conducted and the average of the results was reported.

To determine the effect of feed solution on the chemical structure of the membrane, FTIR studies were conducted on the membranes after immersion in the feed solution (ECH/IPA/ water, $50: 30: 20 \mathrm{w} / \mathrm{w}$ ) at $60{ }^{\circ} \mathrm{C}$ for 15 days.

Similarly, for determination of morphological changes in the membrane structure after immersion in the feed solution (ECH/ IPA/water, $50: 30: 20 \mathrm{w} / \mathrm{w}$ ) at $60^{\circ} \mathrm{C}$ for 15 days, FE-SEM analysis was conducted before and after the immersion of the membrane samples.

Degree of membrane swelling (SD). The dried homogeneous membrane samples were weighed $\left(m_{\mathrm{d}}\right)$, immersed in only ECH and $50: 30: 20$ and $55: 35: 10$ (ECH/IPA/water, w/w, \%) mixtures $\left(50 \mathrm{~cm}^{3}\right)$, and placed in an oven (Memmert, UN55) for $48 \mathrm{~h}$ at $50{ }^{\circ} \mathrm{C}$ to achieve sorption equilibrium. Subsequently, the swollen membranes were removed, wiped with dry tissue paper and weighed immediately. The swelling degree was calculated using eqn (1), where $m_{\mathrm{s}}$ and $m_{\mathrm{d}}$ are the masses of the swollen and dried membranes, respectively.

$$
\mathrm{SD}=\frac{m_{\mathrm{s}}-m_{\mathrm{d}}}{m_{\mathrm{d}}} \times 100
$$

None of the membranes showed any affinity for ECH in the swelling test, and hence the degree of swelling for pure $\mathrm{ECH}$ solution was not reported. Three consecutive measurements were carried out for the swelling study, and average values with standard deviations less than 5 were reported.

\section{Contact angle measurements}

In order to assess the hydrophilicity of all of the membranes (PVAm0 to PVAm1.5), contact angle tests were carried out. The sessile droplet method was used, and the static contact angles of the water droplet on the membrane were measured with the help of a contact angle analyzer (Phoenix 300, South Korea) equipped with a video camera. For each sample, the contact angle of the water droplet was measured ten seconds after placing it onto the membrane. According to the shape of the droplet on the membrane, the corresponding contact angle was calculated with the precision and accuracy provided by the supplied software. Average values of three successive measurements for each sample were reported.

\section{Pervaporation apparatus and measurements}

The pervaporation experiment for the ECH/IPA/water feed mixture was carried out on the same apparatus as used in our previous study. ${ }^{\mathbf{1 4}}$ Briefly, the membranes were placed in a membrane cell and the feed mixture was pumped across the

Table 1 Membranes of PVA and its blends with PVAm, and the corresponding PSI values

\begin{tabular}{|c|c|c|c|}
\hline \multirow[b]{2}{*}{ Designation } & \multicolumn{2}{|c|}{ Ratio in the membrane $\left(\mathrm{g} \mathrm{g}^{-1}\right)$} & \multirow[t]{2}{*}{$\begin{array}{l}\text { Pervaporation separation } \\
\text { index }\end{array}$} \\
\hline & $\begin{array}{l}\text { PVA (poly(vinyl } \\
\text { alcohol)) }\end{array}$ & $\begin{array}{l}\text { PVAm (poly(vinyl } \\
\text { amine)) }\end{array}$ & \\
\hline PVAm0 & 100 & 0 & 47 \\
\hline PVAm0.5 & 100 & 10 & 16 \\
\hline PVAm1.0 & 100 & 20 & 20 \\
\hline PVAm1.5 & 100 & 30 & 19 \\
\hline
\end{tabular}


membrane surface. The effective area of each membrane was $0.0019643 \mathrm{~m}^{2}$ at a flow rate of $70 \mathrm{~g} \mathrm{~min}^{-1}$. A vacuum pump (Edwards, RV8) was used to maintain the pressure of the permeate side at less than 10 mbar. The feed solution tank was maintained at the desired temperature $\left(30{ }^{\circ} \mathrm{C}\right)$. The permeant vapors were collected in a cold liquefied nitrogen trap and then weighed. The feed was an azeotropic mixture with the composition ECH/IPA/water (50:30:20, w/w, \%). The exact compositions of the permeate solutions were determined using a gas chromatograph configured with a TCD detector (DS Sci. DS7200). The pervaporation flux, separation factor, flux of individual components and pervaporation separation index (PSI) of each membrane were calculated using the following equations:

$$
\operatorname{Flux}(J)=\frac{M}{A \times t}
$$

where $M$ is the weight of the permeated solution collected in the cold trap $(\mathrm{kg})$. The flux $\left(\mathrm{kg}\left(\mathrm{m}^{2} \mathrm{~h}^{-1}\right)\right)$ was calculated with respect to the effective area $(A)\left(\mathrm{m}^{2}\right)$ in time $t(\mathrm{~h})$.

Here in this study, the target component is water dehydrated from organics; therefore, separation factors were calculated only for water with respect to the organic components (IPA + $\mathrm{ECH})$ in the ternary feed mixture system. ${ }^{36}$

$$
\text { Separation factor }(\alpha)=\frac{\frac{P_{\text {water }}}{P_{(\mathrm{IPA}+\mathrm{ECH})}}}{\frac{F_{\mathrm{water}}}{F_{(\mathrm{IPA}+\mathrm{ECH})}}}
$$

where $P_{\text {water }}, P_{(\mathrm{IPA}+\mathrm{ECH})}, F_{\text {water }}$, and $F_{(\mathrm{IPA}+\mathrm{ECH})}$ are the weight fractions of water and the ECH + IPA organics solution in the permeated solution and feed solution, respectively.

$$
\text { Flux of individual component }\left(J_{\mathrm{i}}\right)=\frac{J_{\mathrm{i}} \times P_{\mathrm{i}}}{100}
$$

where $J_{\mathrm{i}}$ is the flux of individual component $\mathrm{i}\left(\mathrm{kg}\left(\mathrm{m}^{2} \mathrm{~h}\right)^{-1}\right)$, and $P_{\mathrm{i}}$ corresponds to the weight fraction of component i (ECH, IPA or water) in the permeate solution (wt\%).

The PSI was calculated as:

$$
\text { Pervaporation separation index }(\mathrm{PSI})=J \times(\alpha-1)
$$

where $J$ and $\alpha$ are the flux and separation factor, respectively.

\section{Results and discussion}

\section{Membrane characterization and stability}

Based on FTIR data for the PVA/PVAm blended membrane reported in our previous article ${ }^{33}$ and that of glutaraldehydecrosslinked PVA membranes in the literature, ${ }^{33,37}$ the postulated reaction mechanism for PVA-glutaraldehyde crosslinking and blending of PVA/PVAm with the glutaraldehyde-crosslinked membrane under acidic catalytic conditions is shown in Fig. 1a and $b$. The reactions were confirmed from the FTIR (ATR mode) spectra (Fig. 2(a)-(d)), and Tables 2 and 3 list the corresponding FTIR (ATR mode) vibrations. In order to determine the effect of the ECH-containing feed solution on the chemical structure of the membrane, IR studies of the membrane were performed after immersion in the feed containing $50: 30: 20 \mathrm{ECH} / \mathrm{IPA} /$ water $(\mathrm{w} / \mathrm{w}, \%)$ at $60{ }^{\circ} \mathrm{C}$ for 15 days. Fig. 2(a) shows that the ECH-containing feed mixture at $60^{\circ} \mathrm{C}$ had no effect on the PVAcrosslinked membrane, because all of the FTIR spectra show the same FTIR vibrational frequency for multiple days of membrane sample immersion.

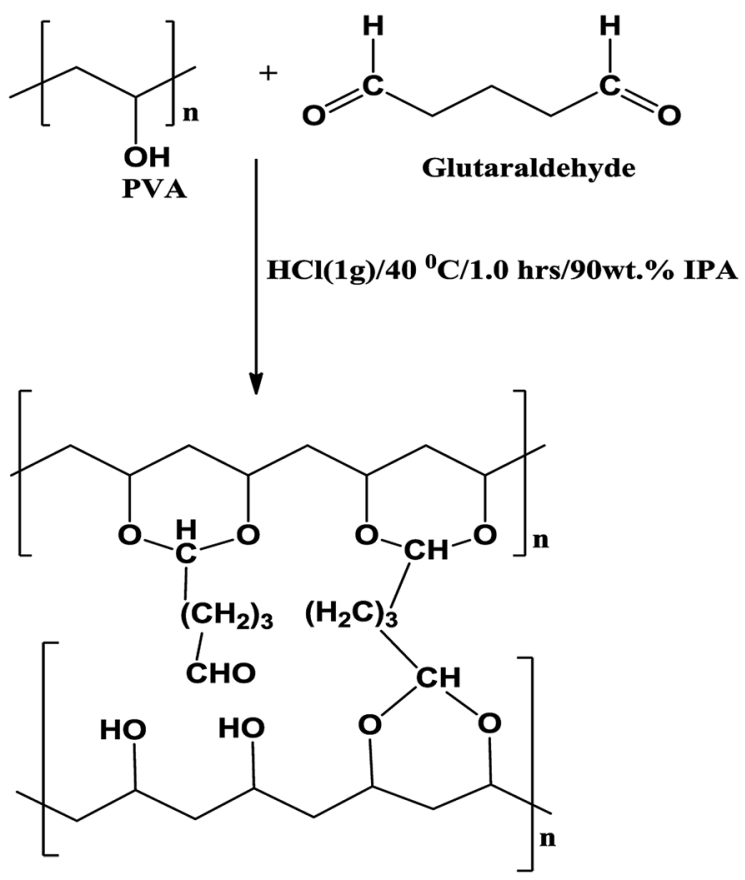

(a)
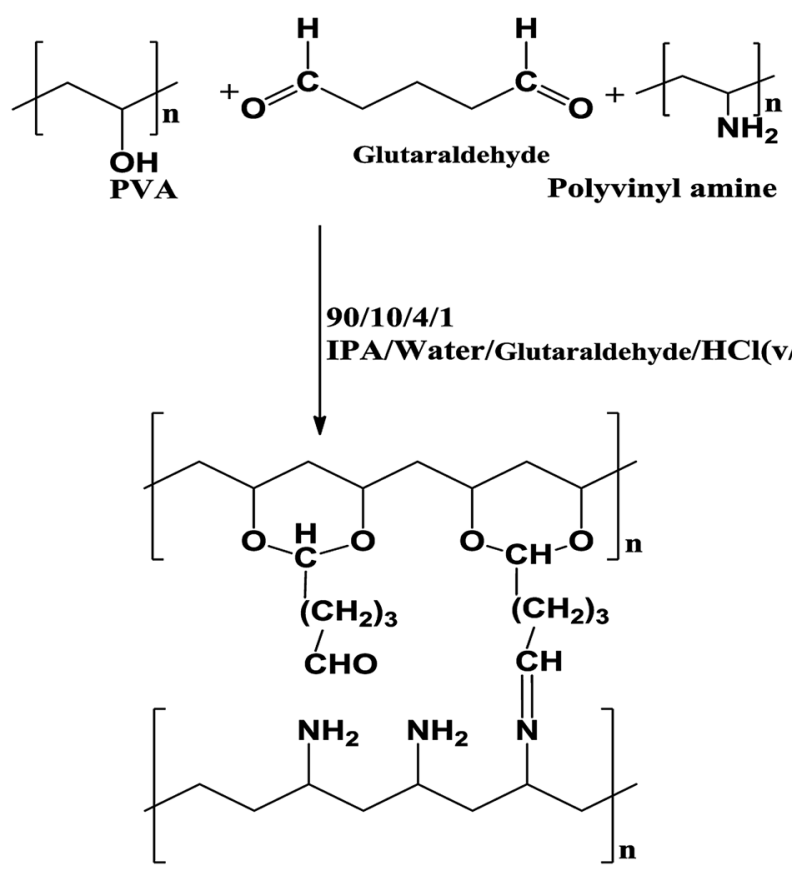

(b)

Fig. 1 Postulated crosslinking reaction schemes for (a) PVA-glutaraldehyde and (b) PVA-PVAm-glutaraldehyde blend membranes. 

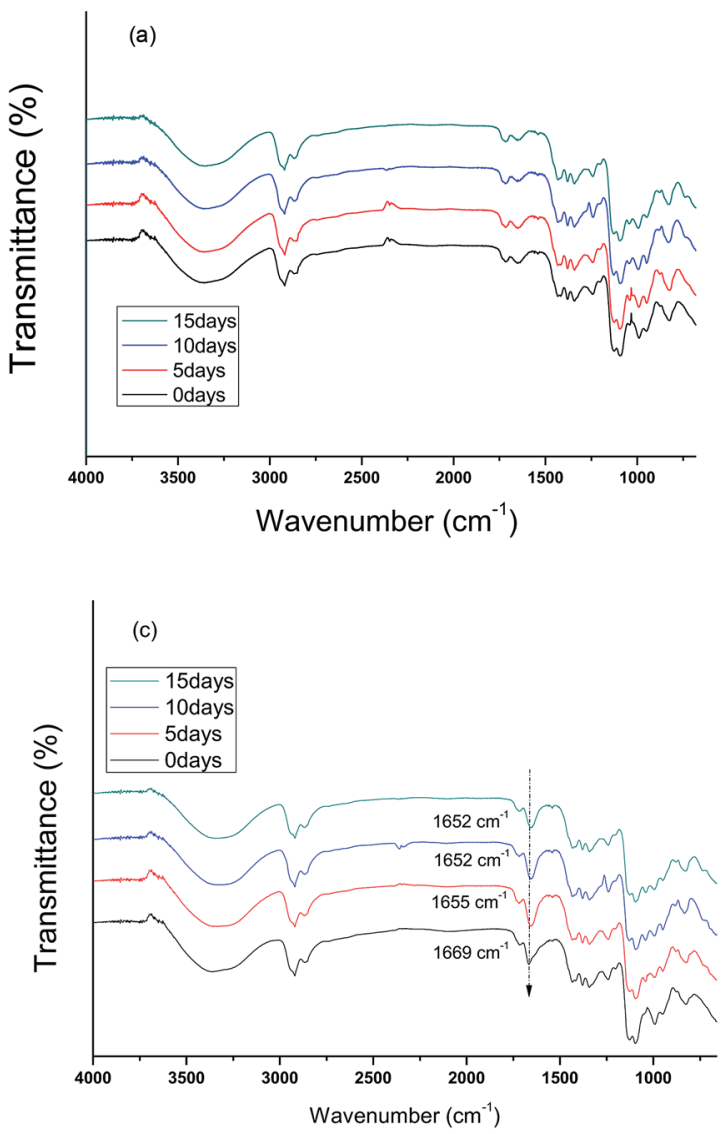
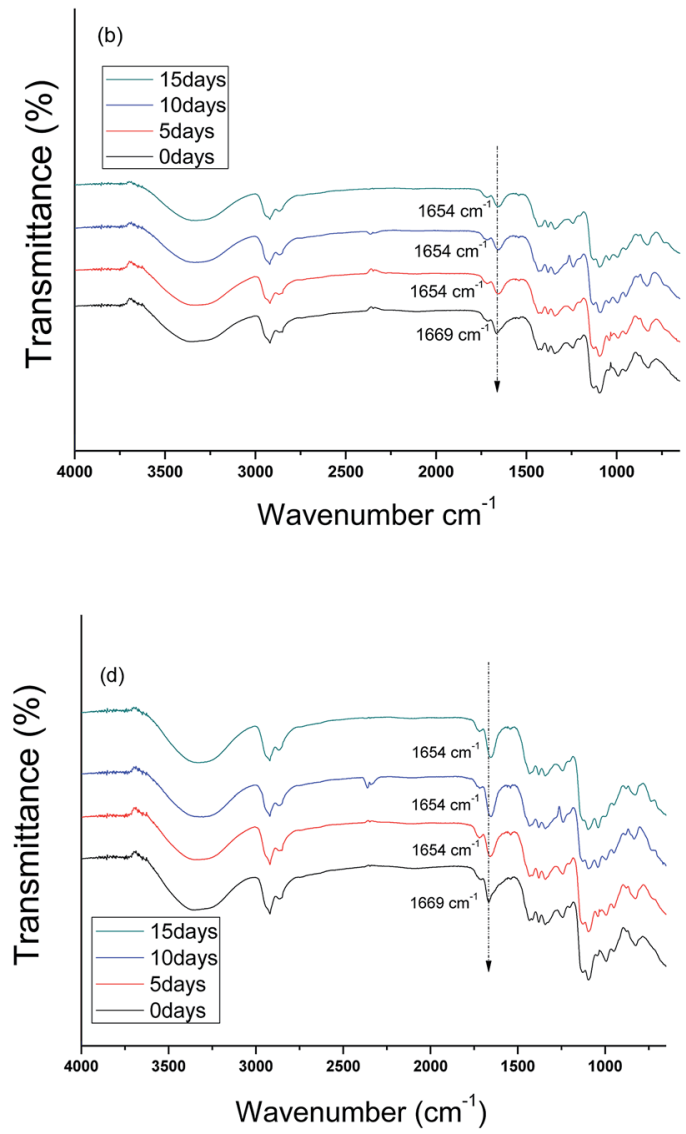

Fig. 2 The FTIR spectra on different days after immersion of (a) PVAm0, (b) PVAm0.5, (c) PVAm1.0 and (d) PVAm1.5 membranes in the $50: 30: 20 \mathrm{ECH} / \mathrm{IPA} /$ water (w/W) feed mixture solution at $60^{\circ} \mathrm{C}$.

However, in the FTIR spectra of the blended membranes (Fig. 2(b-d)), the vibrational frequencies at $1630-1669 \mathrm{~cm}^{-1}$ corresponding to the $\mathrm{C}=\mathrm{N}$ group due to the crosslinking of PVAm and glutaraldehyde (refer to the reaction scheme) slightly shifted to lower wavenumbers. This was possibly because of the presence of highly hydrophilic $\mathrm{OH}$ and $\mathrm{NH}_{2}$ groups in the blended membranes, which, upon prolonged immersion in the water-containing mixture, resulted in intermolecular hydrogen bonding with the imine. Peak shifts to lower or higher wavenumbers have been observed for hydrogen-bonded peaks. ${ }^{38}$ Nevertheless, no additional peak corresponding to ECH was

Table 2 FTIR (ATR mode) peak table for the PVA (glutaraldehyde crosslinked, PVAm0) membrane

IR vibrational

frequency $\left(\mathrm{cm}^{-1}\right)$ Functional moiety

\begin{tabular}{|c|c|}
\hline 3320 & $\begin{array}{l}\text { OH stretching groups in PVA } \\
\text { (inter and intramolecular hydrogen bonding) }\end{array}$ \\
\hline 720 & $\begin{array}{l}\mathrm{C}=\mathrm{O} \text { stretching from aldehyde } \\
\text { (remaining) after crosslinking }\end{array}$ \\
\hline 2860 & $\mathrm{C}-\mathrm{H}$ stretching from aldehyde \\
\hline 2925 & $\begin{array}{l}\text { Asymmetric and symmetric stretching } \\
\text { of } \mathrm{CH}_{2} \text { groups in PVA }\end{array}$ \\
\hline $80-1135$ & $\begin{array}{l}\mathrm{C}-\mathrm{O}-\mathrm{C} \text {, acetal formation after the glutaraldehyde } \\
\text { and hydroxyl group in the PVA crosslinking reacti }\end{array}$ \\
\hline
\end{tabular}

observed. Therefore, it was suggested that all of the membranes were chemically stable for 15 days of immersion in the $50: 30: 20 \mathrm{ECH} / \mathrm{IPA} /$ water $(\mathrm{w} / \mathrm{w}, \%)$ feed mixture at $60{ }^{\circ} \mathrm{C}$.

\section{Field-emission scanning electron microscopy analysis}

FESEM analysis was performed in order to assess the morphological stability of the membranes in the ECHcontaining feed mixture. The surface and cross-sectional

Table 3 FTIR (ATR mode) peak table for the PVA/PVAm-glutaraldehyde crosslinked blended membranes

IR vibrational

frequency $\left(\mathrm{cm}^{-1}\right)$

Functional moiety

$3320-3600$

$1630-1669,1720$

1250-1255

2860

2925

1080-1135
$\mathrm{NH}_{2}$ and $\mathrm{OH}$ groups (stretching vibration) from PVA and PVAm

$\mathrm{C}=\mathrm{N}$ from imine, $\mathrm{C}=\mathrm{O}$ stretching vibration in amide (presence of unhydrolyzed amide groups in PVAm from PVNF) and remaining aldehyde groups in the glutaraldehyde after the crosslinking

$\mathrm{C}-\mathrm{N}$ stretching vibration in amine $\mathrm{C}-\mathrm{H}$ stretching from aldehyde Asymmetric and symmetric stretching of $\mathrm{CH}_{2}$ groups in PVA and PVAm $\mathrm{C}-\mathrm{O}-\mathrm{C}$ acetal formation after PVA-glutaraldehyde crosslinking 
morphologies of all of the membranes before and after immersion in the feed (50:30:20, ECH/IPA/water) (w/w, \%) at $60{ }^{\circ} \mathrm{C}$ for 15 days were investigated by FESEM. Images before immersion are shown in Fig. 3a, which indicates that upon blending with PVAm, a continuous and compact homogeneous dense surface structure with no voids or phase separation was obtained. This result confirms that both polymers have good compatibility and are mixed at the molecular level owing to the presence of hydrogen bonds between the several functional moieties $\left(\mathrm{NH}_{2}, \mathrm{OH}, \mathrm{C}=\mathrm{N}\right.$, and $\left.\mathrm{C}=\mathrm{O}\right)$. Fig. 3b shows the FESEM images for the membranes after immersion in ECH/IPA/water $(50: 30: 20)(\mathrm{w} / \mathrm{w}, \%)$ at $60{ }^{\circ} \mathrm{C}$. No surface degradation or membrane damage and phase separation phenomena are detected for the PVAm0 and PVAm0.5 membranes. However, for PVAm1.0 and PVAm1.5, hole generation or polymer phase extraction phenomena can be detected. The morphologies of PVAm0 and PVAm0.5 are very compact, even when immersed at high temperature, suggesting that the membranes are suitable for pervaporation at high temperature with highly reactive ECH-containing feed mixtures. Nevertheless, FESEM images for the PVAm1.0 and PVAm1.5 membranes (Fig. 3b) clearly show that a higher content of amine functional moieties increases the hydrophilicity and hence swelling of the membrane, resulting in microscopic phase extraction in the ECH-containing feed, which damages the membrane surface. Therefore, membranes with higher PVAm content do not possess long-term stability in the ECH-containing feed mixture.
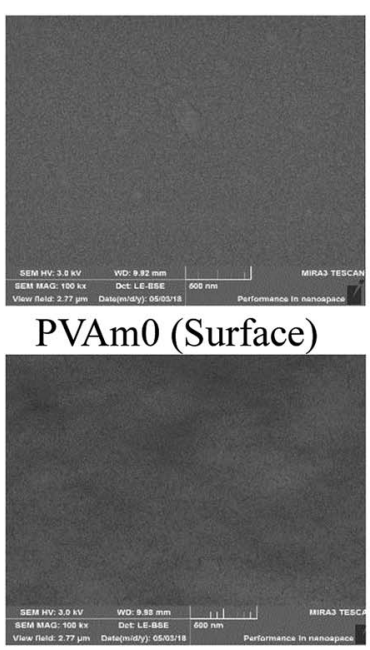

PVAm0 (Crosssection)
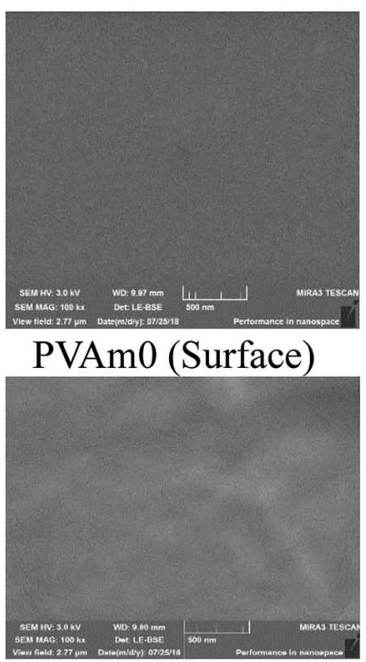

PVAm0 (Crosssection)
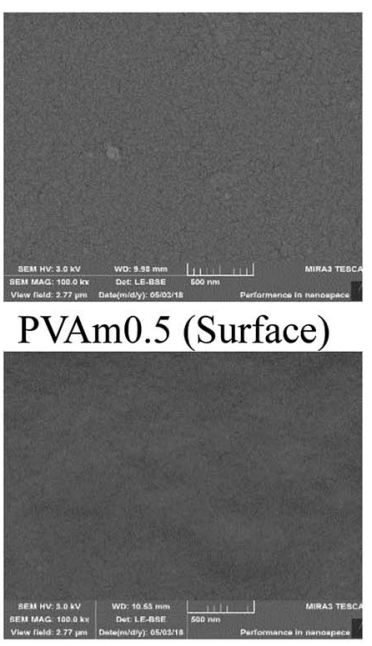

PVAm0.5 (Crosssection)

(a)
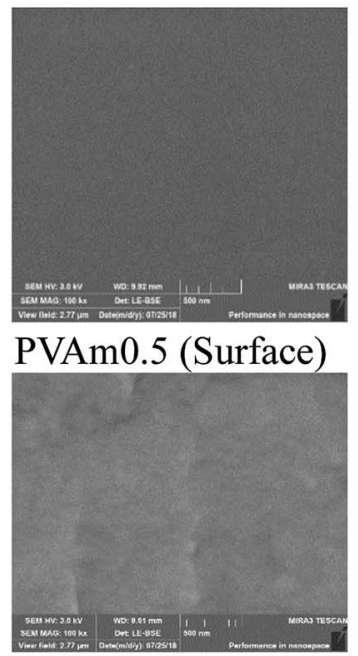

PVAm0.5 (Crosssection)
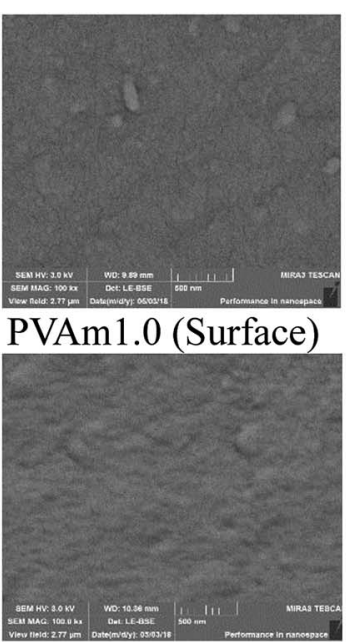

PVAm1.0 (Crosssection)
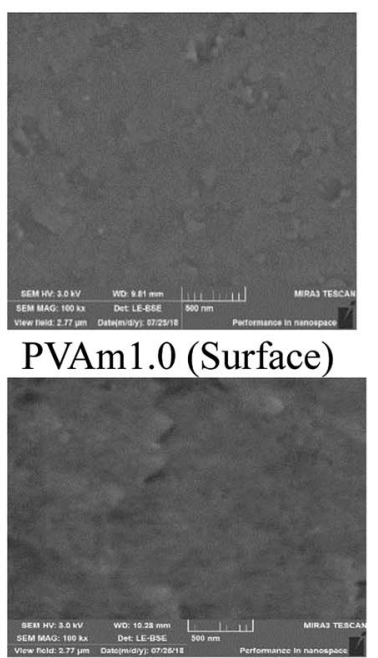

PVAm1.0 (Crosssection)
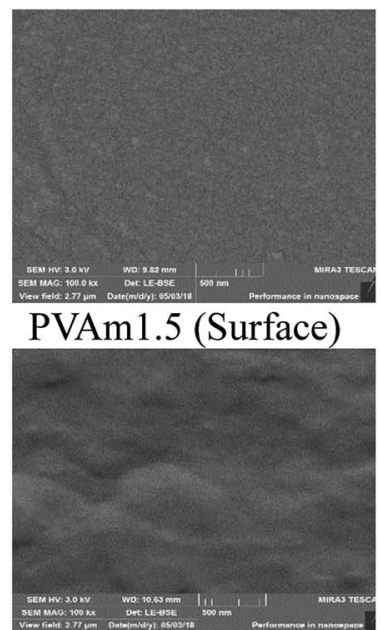

PVAm1.5 (CrossSection)
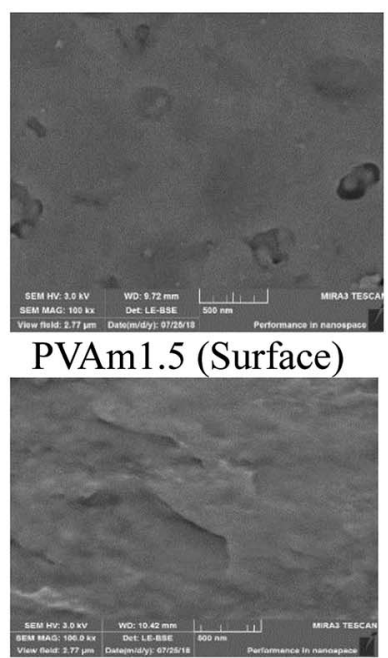

PVAm1.5 (CrossSection)

(b)

Fig. 3 SEM micrographs of the PVAm0, PVAm0.5, PVAm1.0, and PVAm1.5 membranes (a) before and (b) after immersion in the $50: 30: 20$ ECH/ IPA/water (w/w) feed mixture solution at $60^{\circ} \mathrm{C}$. 


\section{Loss or gain in weight}

Fig. 4 shows that with increase in the number of immersion days, the membrane weights increased marginally; however, after washing the film with water (deep immersion of the membrane in water at $25{ }^{\circ} \mathrm{C}$ for $2 \mathrm{~h}$ ), the weight of the membrane decreased to nearly the initial weight. Additionally, Fig. 5 shows that even after 15 days of membrane immersion in the $50: 30: 20 \mathrm{ECH} / \mathrm{IPA} /$ water $(\mathrm{w} / \mathrm{w}, \%)$ solution at $60{ }^{\circ} \mathrm{C}$, the solution remained clear and colorless, suggesting that no visible membrane extraction occurred. However, FESEM analysis confirmed that PVAm1.0 and PVAm1.5 were unstable at high temperature in the ECH-containing feed mixture. Fig. 6 shows the physical condition of the membranes before and after immersion; clearly, the membranes maintain their structural integrity, with no visible breakage or damage.

\section{Degree of membrane swelling}

The affinity between the membrane materials and permeating molecules can be quantitatively estimated by a sorption test. In the 1950s, Flory and Rehner reported ${ }^{39}$ that the extent of membrane swelling in specific liquids relies on the crosslinking density, morphology of the membrane, and free volume available in the membrane matrix, which strongly affect the sorption mechanism. Therefore, it is necessary to determine the degree of swelling, because it controls the mass transfer of the permeating molecules under a concentration gradient in the PV process. As explained in the introduction section, ECH/IPA/ water form an azeotropic mixture at 50/30/20 w/w, \%. By assuming that the long-term pervaporation operation will result in the continuous dehydration of the above feed mixture, it should be possible to decrease the water concentration in the feed mixture and consequently affect the permeation rate of the membrane. Additionally, polymer membranes are recognizably affected by the operating temperature in pervaporation. It is possible to estimate how the permeation rate is affected by temperature by measuring membrane swelling. ${ }^{40}$ Therefore, in

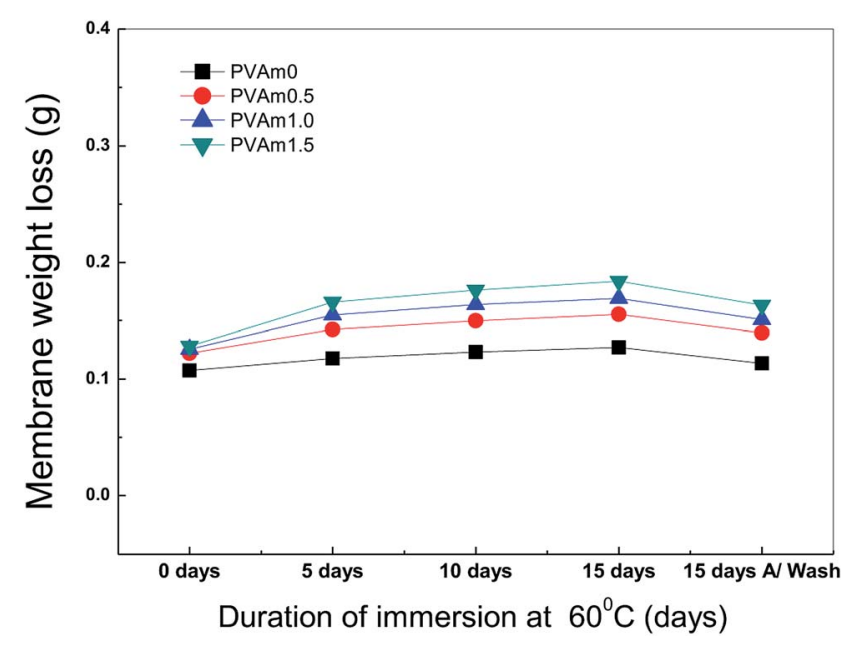

Fig. 4 Loss/gain in weight of the membranes after 15 days of immersion in the $50: 30: 20 \mathrm{ECH} / \mathrm{IPA} /$ water $(\mathrm{w} / \mathrm{w})$ feed mixture solution at $60^{\circ} \mathrm{C}$. this study, a swelling study for two different feed conditions was performed at $30{ }^{\circ} \mathrm{C}$ and $50{ }^{\circ} \mathrm{C}$. Fig. 7 shows the effect of feed concentration and membrane composition on the degree of swelling of the membranes at $30{ }^{\circ} \mathrm{C}$ and $50{ }^{\circ} \mathrm{C}$. The SD value of the membranes increased linearly with increasing poly(vinyl amine) content in the membrane composition. This is due to increased hydrophilicity arising from the amine and amide functionalities in the blended membrane, which increase the affinity of the membrane with water. In order to support this explanation, we have studied the effect of PVAm content on the contact angle of a water droplet on the membrane surface. As can be seen from Fig. 8, the contact angle of a water droplet on the membrane decreased with a higher content of PVAm in the blended membrane, which indicated that the hydrophilicity of the membrane increased with increasing PVAm content in the membrane. On other hand, the SD value of all of the membranes increased with increasing volume of water in the feed and with the feed temperature. This is because more water in the feed increases the driving force for water absorption, resulting in a plasticization phenomenon of the membrane. Also, with an increase in the feed temperature, the mobility of the polymer chains increases, and consequently, swelling of the amorphous regions in the membranes occurs. The SD values obtained here are relatively higher than those for conventional binary or ternary mixture systems, possibly because of the higher density of ECH $\left(1.18 \mathrm{~g} \mathrm{~mL}^{-1}\right)$ than water and IPA. Even though all membranes showed no affinity for $\mathrm{ECH}$, the plasticization of the membrane due to water in the feed caused the absorption of IPA and ECH in the membrane. Moreover, the absorption of ECH was greater than that of IPA, which is further explained in the pervaporation section. Thus, the SD values are relatively high for all membranes.

\section{Pervaporation}

In the manufacture of epoxy resins, as explained in the introduction section, by-products and excess ECH and IPA remain. Therefore, during the recovery of ECH and IPA by distillation, an azeotropic ternary feed mixture solution (50 wt\% ECH, $30 \mathrm{wt} \%$ IPA, and $20 \mathrm{wt} \%$ water) is formed, so we used the same feed mixture composition for the pervaporation dehydration. Fig. 9 shows the effects of the PVA/PVAm blending ratio on the flux and separation factor at $30{ }^{\circ} \mathrm{C}$, which clearly shows the ability of PVA-PVAm blend membranes to dehydrate the ternary liquid-liquid equilibrium mixture of ECH/IPA/water via the pervaporation process. As the PVAm amount increased from PVAm0 to PVAm1.5, the flux increased from 0.025 to $0.32 \mathrm{~kg}\left(\mathrm{~m}^{2}\right.$ h) ${ }^{-1}$, respectively, and the separation factor decreased monotonously with the PVAm content.

PVA and PVAm are linear aliphatic hydrophilic semicrystalline polymers. On the crosslinking of PVA with glutaraldehyde, the membrane became dense and compact due to shrinkage of the polymer chains, reducing the flux; however, in the blend membrane, the addition of PVAm increased the hydrophilicity of the membrane by introducing a large number of primary amine groups. ${ }^{32}$ Additionally, the intermolecular hydrogen bonding interaction of $\mathrm{NH}_{2}$ and $\mathrm{OH}$ in the blend 


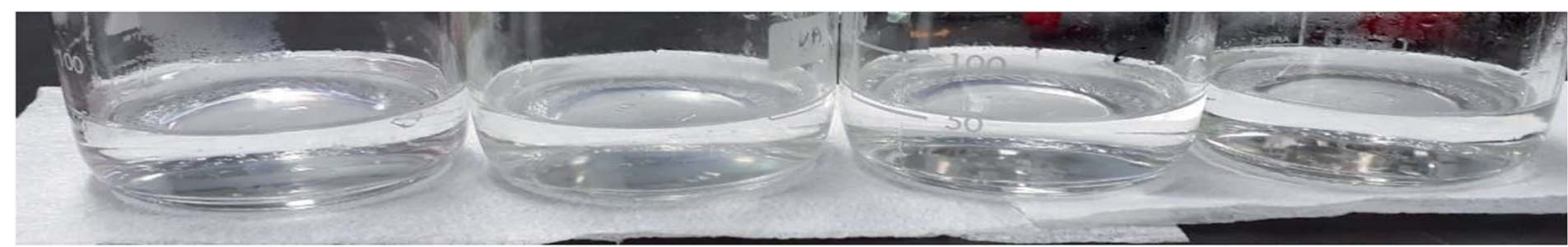

Fig. 5 Clarity of the $50: 30: 20 \mathrm{ECH} / \mathrm{PA} /$ water (w/w) feed mixture solution after 15 days of immersion.

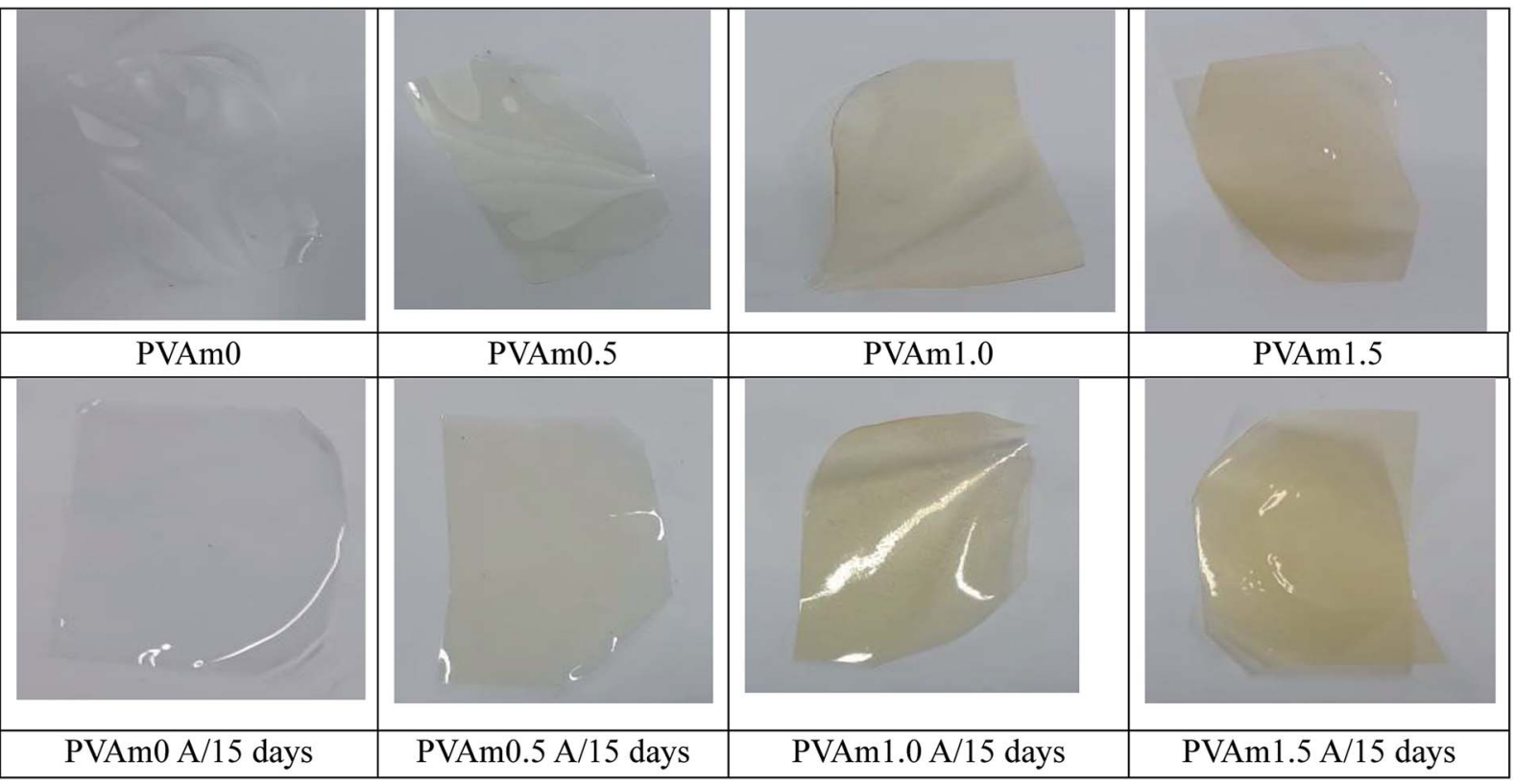

Fig. 6 Physical status of the membranes after 15 days of immersion in the ECH/IPA/water $\left(50: 30: 20\right.$, w/w) feed mixture solution at $60{ }^{\circ} \mathrm{C}$.

membrane disturbs the order of the chains in both semicrystalline polymers, and this increases the free volume of the membrane. Moreover, according to the fixed carrier theory, the transport of water molecules through the membrane takes place from one polar site to another. ${ }^{41}$ Therefore, the combination of PVA and PVAm increases the number of hydrophilic functional moieties $\left(\mathrm{OH}, \mathrm{NH}_{2},-\mathrm{NH}-\mathrm{CH}=\mathrm{O}\right)$ in the membrane, which enhances the hydrophilic-hydrophilic and hydrogen bonding interactions. This in turn improves the water molecule sorption and subsequent diffusion through the membranes responsible for the increment of flux. On the other hand, as observed from the swelling study, highly hydrophilic sites in the amorphous region of the blended membrane resulted in higher water sorption and in the plasticization of the membrane. Even though ECH and IPA do not have an affinity for the membrane, the plasticization phenomenon due to absorption of water in the membrane results in a higher chain gap and allows the penetration of organics along with water molecules. Hence, the separation factor value for the blended membranes was lower than that for the PVA crosslinked membrane.

Fig. 10 depicts the individual fluxes for ECH, IPA, and water; this figure shows that the total permeation through all the membranes was controlled by water, since the water flux is very close to the total permeation flux in the dehydration of ECH/ IPA/water $(50: 30: 20, \mathrm{w} / \mathrm{w})$ at $30{ }^{\circ} \mathrm{C}$. Nevertheless, it is interesting to note from the figure that, although ECH has a larger molecular size than IPA, the permeation rate of ECH is higher than that of IPA. This is because, generally, in pervaporation dehydration through a hydrophilic membrane, water can interact with an active center in the membrane via hydrogen

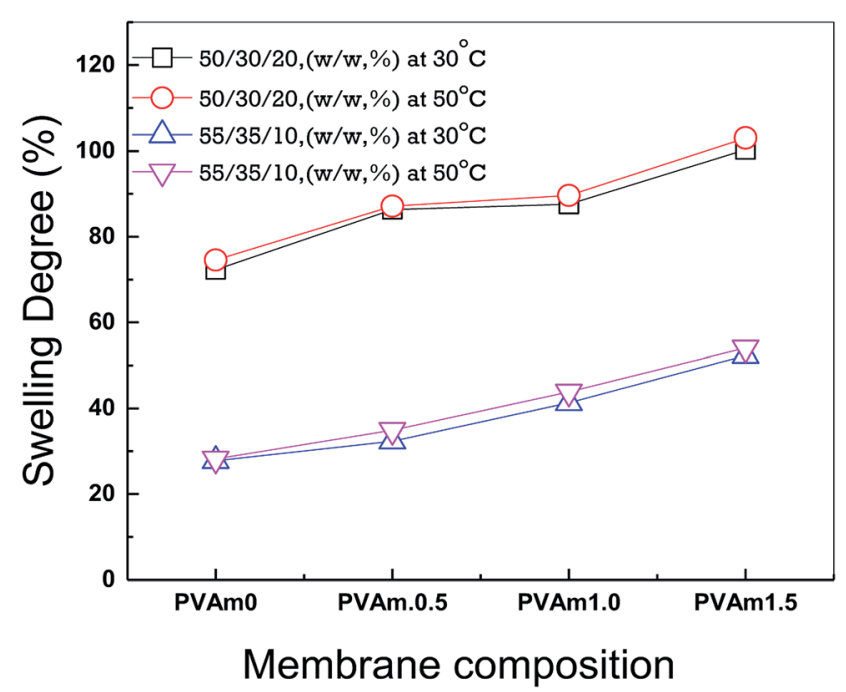

Fig. 7 Effect of ECH/IPA/water feed concentration (w/w) and PVA/PVAm composition on the membrane swelling degree at $30^{\circ} \mathrm{C}$ and $50{ }^{\circ} \mathrm{C}$. 


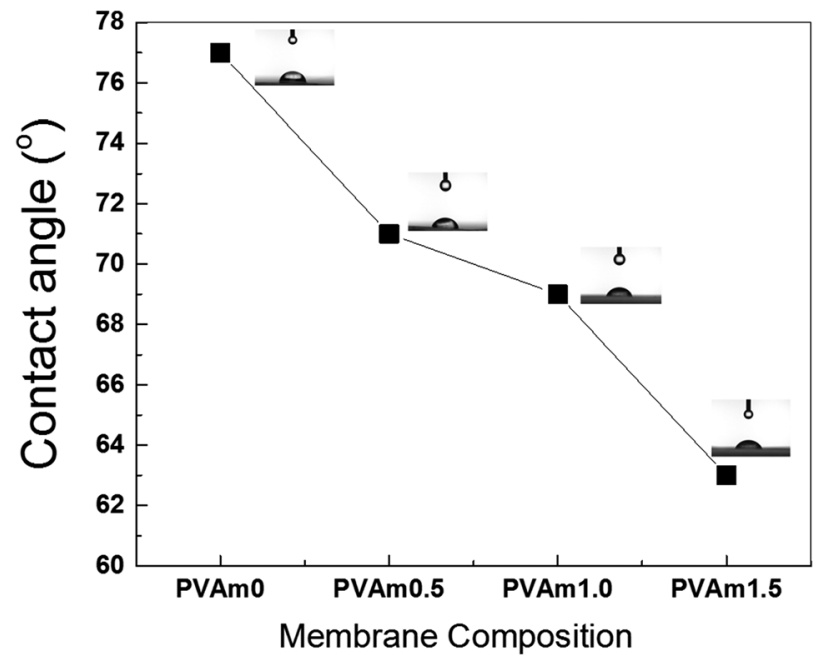

Fig. 8 Effect of PVAm content on the membrane hydrophilicity by contact angle measurement.

bonding, dipole-dipole and ion-dipole interactions. ${ }^{26}$ Therefore, it is possible that ECH has dipole-dipole interactions with $\mathrm{OH}, \mathrm{NH}_{2}, \mathrm{C}=\mathrm{N}$, and $\mathrm{C}=\mathrm{O}$ in the membrane, and this might be the cause of the flux being higher than the IPA flux, since ECH is a polar molecule. Additionally, a higher content of ECH in the feed composition (50 wt\%) increases the driving force in the feed boundary layer for its absorption on the feed side of the membrane. This resulted in a higher permeation rate of ECH in comparison to that of IPA. The PVAm0 membrane showed the highest PSI (refer to Table 1) value, since the PSI is the product of the flux and separation factor. So, even though the flux of the blended membrane was $\sim 10$ times higher than that of the PVAglutaraldehyde membrane, the separation factor obtained from the blended membrane was comparatively lower $(\sim 32)$ than that of the PVA-glutaraldehyde membrane (PVAm0). Additionally, it was observed from the FE-SEM analysis of the blended membranes that the blended PVA/PVAm membranes with a higher content of PVAm were not stable in the ECH-containing feed mixture. It can be concluded that the PVA-glutaraldehyde crosslinked membrane (PVAm0) has the potential to

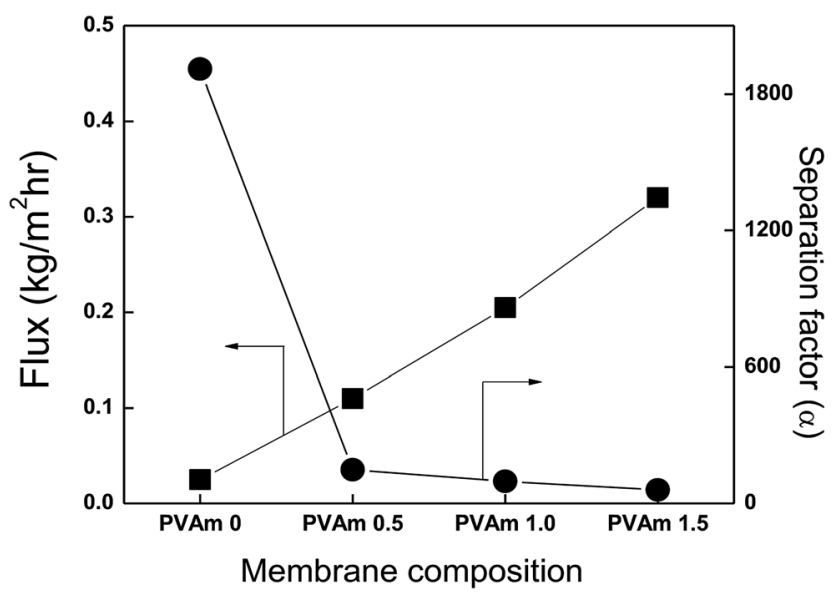

Fig. 9 Effect of membrane composition on flux and separation factor, at $30{ }^{\circ} \mathrm{C}$ with the ECH/IPA/water (50:30:20, w/w) feed; thickness: $65 \mu \mathrm{m}$.

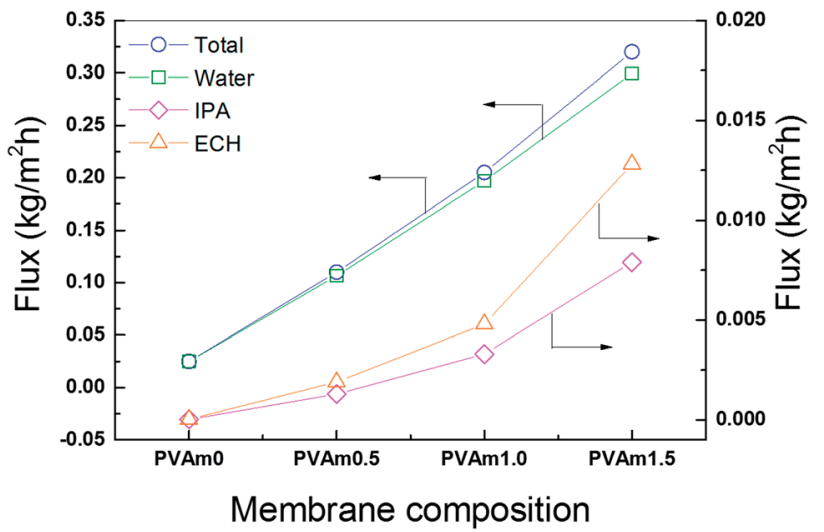

Fig. 10 Individual fluxes of ECH, IPA, and water at $30^{\circ} \mathrm{C}$; feed: $\mathrm{ECH}$ / IPA/water (50: $30: 20, \mathrm{w} / \mathrm{w}$ ); thickness: $65 \mu \mathrm{m}$.

dehydrate the highly reactive ECH-containing feed mixture. On the other hand, in the case of the blended membranes, there was no significant change in PSI value observed, suggesting that the blended membranes are comparatively less stable in the ECH-containing feed solution.

\section{Conclusion}

The stability and pervaporation efficiency of membranes composed of PVA and its blend with PVAm in a highly reactive ECH-containing ternary mixture feed system were studied. From FTIR, and physical examination of the membranes, it was concluded that all of the membranes were physically, mechanically, and chemically stable for up to 15 days in the ECH-containing feed mixtures. The weights of all of the membranes were constant up to 15 days, suggesting that there was no extraction of the polymer in the $50: 30: 20 \mathrm{ECH} / \mathrm{IPA} /$ water $(\mathrm{w} / \mathrm{w})$ solution at $60{ }^{\circ} \mathrm{C}$. However, in the FE-SEM analysis, in the case of the PVA/PVAm blended membranes, the microscopic extraction of the polymer phase in the membranes for $50: 30: 20 \mathrm{ECH} / \mathrm{IPA} /$ water solution at $60{ }^{\circ} \mathrm{C}$ was observed. The pervaporation dehydration of this azeotropic mixture at $30{ }^{\circ} \mathrm{C}$ was performed, and all of the membranes showed remarkable pervaporation dehydration efficiency. The flux increased from 0.025 to $0.32 \mathrm{~kg}\left(\mathrm{~m}^{2} \mathrm{~h}\right)^{-1}$, and the separation factor decreased from 1908 to 60 with increasing PVAm content in the blended membrane. From the PSI data and FE-SEM images for all of the membranes (PVAm0 to PVAm1.5) after immersion in the mixture at $60{ }^{\circ} \mathrm{C}$, it was concluded that the blended membranes are relatively less stable than the glutaraldehyde-crosslinked-PVA (PVAm0) membrane.

\section{Conflicts of interest}

There are no conflicts to declare.

\section{Acknowledgements}

This work was supported by the New \& Renewable Energy Core Technology Program of the Korea Institute of Energy Technology Evaluation and Planning (KETEP) and the financial 
resources granted by the Ministry of Trade, Industry \& Energy of the Republic of Korea (No. 20172010106170).

\section{References}

1 M. I. Baig, P. G. Ingole, W. Choi, S. Park, E. Kang and H. Lee, J. Membr. Sci., 2016, 514, 622.

2 P. G. Ingole, M. I. Baig, W. Choi, X. An, W. Choi and H. Lee, J. Ind. Eng. Chem., 2017, 48, 5.

3 P. G. Ingole, W. Choi, G. Lee and H. Lee, Desalination, 2017, 403, 12.

4 P. G. Ingole, M. Sohail, A. Abou- Elanwar, M. Baig, J. Jeon, W. Choi, H. Kim and H. Lee, Chem. Eng. J., 2018, 334, 2450.

5 P. G. Ingole, W. Choi, H. Kim, C. Park, W. K. Choi and H. Lee, Chem. Eng. J., 2014, 243, 137.

6 J. G. Wiljmans and R. W. Baker, J. Membr. Sci., 1995, 107, 1. 7 P. D. Chapman, T. Oliveira, A. G. Livingston and K. Li, J. Membr. Sci., 2008, 318, 5.

8 G. F. Tusel and H. E. A. Bruschke, Desalination, 1985, 53, 327.

9 I. Souchon, F. X. Pierre, V. Athes-Dutour and M. Marin, Desalination, 2002, 148, 79.

10 C. S. Slater, M. J. Savelski, T. M. Moroz and M. J. Raymond, Green Chem. Lett. Rev., 2012, 5, 55.

11 M. Aliabadi, A. Aroujalian and A. Raisi, Desalination, 2012, 248, 16.

12 Q. Li, Q. Liu, J. Zhao, Y. Hua, J. Sun, J. Duan and W. Jin, J. Membr. Sci., 2017, 544, 68-78.

13 Y. Liao, C. Hu, J. Lai and Y. Liu, J. Membr. Sci., 2017, 531, 10.

14 S. Chaudhari, Y. Kwon, M. Moon, M. Shon, S. Nam and Y. Park, Vacuum, 2018, 147, 115.

15 D. Wu, J. Martin, J. Du, Y. Zhang, D. Lawless and X. Feng, J. Membr. Sci., 2015, 493, 622.

16 V. Chandane, A. Rathod and K. Wasewar, Chem. Eng. Process., 2017, 119, 16.

17 W. Zhang, W. Qing, N. Chen, Z. Ren, J. Chen and W. Sun, J. Membr. Sci., 2014, 451, 285.

18 M. Catarino, A. Ferreira and A. Mendes, J. Membr. Sci., 2009, 341, 51 .
19 S. Tan, L. Li, Z. Xiao, Y. Wu and Z. Zhang, J. Membr. Sci., 2005, 264, 129.

20 L. Aouinti, D. Roizard and M. Belbachir, Sep. Purif. Technol., 2015, 147, 51.

21 R. Qi, Y. Wang, J. Li and S. Zhu, Sep. Purif. Technol., 2006, 51, 258.

22 G. Jungang, J. Appl. Polym. Sci., 1993, 48, 237.

23 C. Chang and W. Lee, J. Appl. Polym. Sci., 2010, 116, 2065.

24 B. Hirakawa, Epichlorohydrin, Encyclopaedia of Toxicology, Elsevier, 3rd edn, 2014, p. 431.

25 P. Wester, C. Heijden, A. Bisschop and G. Esch, Toxicology, 1985, 36, 325-339.

26 S. Semenova, H. Ohya and K. Soontarapa, Desalination, 1997, 110, 251.

27 S. G. Chaudhri, B. H. Rajai and P. S. Singh, $R S C A d v ., 2015,5$, 65862 .

28 T. Jose, S. C. George and S. Thomas, Polym. Eng. Sci., 2018, 58, 849.

29 A. Sajjan, B. Kumar, A. Kittur and M. Kariduraganavar, J. Ind. Eng. Chem., 2013, 19, 427.

30 A. Ariyaskul, R. Y. M. Huang, P. L. Douglas, R. Pal, X. Feng, P. Chen and L. Liu, J. Membr. Sci., 2006, 280, 815.

31 R. S. Veerpur, K. B. Gudasi and T. M. Aminabhavi, J. Membr. Sci., 2007, 304, 102.

32 R. Pelton, Langmuir, 2014, 30, 15373.

33 S. Chaudhari, Y. Kwon, M. Moon, M. Shon, S. Nam and Y. Park, J. Appl. Polym. Sci., 2017, 134, 45572.

34 L. Deng, T. Kim and M. Hagg, J. Membr. Sci., 2009, 340, 154.

35 L. Deng and M. Hagg, J. Membr. Sci., 2009, 363, 295.

36 S. Zhang, Y. Zhou, T. Wei, C. Mu, Z. Liu and Z. Tong, Sep. Purif. Technol., 2017, 173, 314.

37 R. Rudra, V. Kumar and P. Kundu, RSC Adv., 2015, 5, 53436.

38 S. Ma, X. Qi, Y. Cao, S. Yang and J. Xu, Polymer, 2013, 54, 5382.

39 P. J. Flory and J. Rehner, J. Chem. Phys., 1943, 11, 521.

40 R. Y. M. Huang, P. Shao, X. Feng and W. A. Anderson, Ind. Eng. Chem. Res., 2002, 41, 2957.

41 P. Shao and R. Y. M Huang, J. Membr. Sci., 2007, 287, 162. 